\title{
СТРАТЕГИЧЕСКИЕ ПРИОРИТЕТЫ ИННОВАЦИОННОЙ ДЕЯТЕЛЬНОСТИ ВЫСОКОТЕХНОЛОГИЧНЫХ КОМПАНИЙ
}

\author{
(c) 2021 Гаврилюк Артём Владимирович \\ кандидат экономических наук, старший преподаватель кафедры экономики \\ инновационного развития факультета государственного управления \\ Московский Государственный Университет имени М. В. Ломоносова, Россия, Москва \\ E-mail: gavriliuk@spa.msu.ru
}

\section{(C) 2021 Хворостяная Анна Сергеевна}

кандидат экономических наук, ведущий научный сотрудник Центра Стратегических Исследований Института Математических Исследований Сложных Систем Московский Государственный Университет имени М. В. Ломоносова, Россия, Москва E-mail:khvorostyanayaas@gmail.com

В статье раскрыты стратегические особенности организации инновационной деятельности высокотехнологичных компаний. Показана специфика реализации инновационной стратегии, изложены стратегические приоритеты и конкурентные преимущества высокотехнологичных компаний. В работе отмечено, что инновационная стратегия не только помогает концентрировать усилия компании на определенных направлениях долгосрочной деятельности, но и позволяет усилить стратегическое лидерство. Эффективность реализации инновационной деятельности зависит от комбинации инструментов стратегического управления в единой системе, набора последовательных действий, которые обеспечивают поиск уникальных решений производственных и непроизводственных задач, трансформируют идеи в бизнес-концепции и обеспечивают стратегический выбор приоритетных направлений деятельности.

Ключевые слова: стратегическое управление, стратегия, стратегический приоритет, инновации, трансфер технологий, стартап, бизнес-модель, компания.

Стратегические приоритеты инновационной деятельности предполагают приверженность к выбору взаимодополняющих политик (научной, технологической, организационной) и/или моделей управления бизнес-процессами, направленных на достижение конкретной стратегической цели. Эффективные стратегии содействуют согласованию разных видов ресурсов и последовательных этапов реализации инновационной деятельности между различными группами, структурными подразделениями компании, определяют стратегические цели и приоритеты создания инноваций, помогают сконцентрировать усилия на приоритетных направлениях научно-исследовательских, опытноконструкторских и технологических работ (НИOKTP).

Высокотехнологичные конкурентоспособные компании на постоянной основе определяют и пересматривают свои стратегические направления инновационной деятельности, маркетинговую политику, объемы инвестиций в НИОКТР, производственные и непроизводственные задачи, механизмы трансфера, внедрения и освоения технологий. Инновационные компании перманентно направляют ресурсы на поиск новых решений производственных и непроизводственных задач, внедрение перспективных разработок и развитие модели стратегического управления.

Отсутствие эффективной инновационной стратегии может превратить усилия компании в сфере инновационной деятельности в набор передовых практик (разделение трудового коллектива на проектные группы, создание стартапов, развитие внутреннего предпринимательства, формирование венчурного подразделения в компании, развитие стратегических альянсов, создание акселераторов, внедрение концепции открытых инноваций, разработка технологий быстрого прототипирования), не обеспечивающих долгосрочный характер осуществления технологических, организационных и иных нововведений. 
Опыт высокотехнологичных компаний свидетельствует о том, что способность организации к созданию наукоемких изделий базируется на инновационной стратегии, согласованном механизме взаимозависимых процессов и систем, которые определяют действия компании по части поиска революционных решений производственных и непроизводственных задач, синтезируют и трансформируют идеи в бизнесконцепцию и дизайн инновационного продукта [4]. Внедрение в бизнес-процессы компании передовой практики предполагает внесение преобразований в сложившуюся инновационную систему поиска компромиссных решений для перехода на новую технологию, приобретения стартапов и лицензирования патентов.

Не существует универсальной инновационной стратегии и системы управления НИОКТР, которые отвечали бы всем требованиям реализации производственных и непроизводственных процессов различных компаний или работали бы в разнообразных условиях организации бизнеса. Безусловно, нет ничего зазорного в том, чтобы учиться на чужом опыте, применяя инструмент бенчмаркинга в ходе мониторинга внешней среды объекта стратегирования, но ошибочно полагать, что то, что внедряется и работает в Apple будет работать и в другой компании. Эффективная инновационная стратегия, разработанная с учетом факторов внешней и внутренней среды, стратегических возможностей и ресурсов компании, позволяет создать стратегическую систему управления производственными и непроизводственными процессами, соответствующую конкурентным преимуществам компании.

При отсутствии инновационной стратегии различные структурные подразделения компании могут работать над противоречивыми стратегическими приоритетам. Маркетологи могут видеть дополнительные стратегические возможности для укрепления бренда посредством расширения продуктовой линейки или доли рынка. Руководители отделов сбыта сконцентрированы на целевых сегментах рынка и долгосрочных факторах увеличения прибыли. Инженеры-изобретатели проектных подразделений компании склонны видеть новые стратегические возможности в инновационных технологиях и нестандартных научно-технических решениях. Разнообразие взглядов, позиций, мнений, интересов самых разных сторон тру- дового коллектива компании безусловно имеет ключевое значение для создания и реализации стратегических приоритетов в области инновационного развития. Но без интеграции, синергии и согласования разных интересов акторов и лидеров корпоративных подразделений весь стратегический потенциал компании рассеивается и снижает свою экономическую и общественную эффективность.

Процесс разработки инновационной стратегии может осуществляться на базе теории и методологии основоположника отечественной школы стратегирования доктора экономических наук, профессора, иностранного члена РАН, директора Центра Стратегических Исследований Института Математических Исследований Сложных Систем МГУ имени М.В.Ломоносова, заслуженного работника высшей школы Российской Федерации Владимира Львовича Квинта. Его школа занимается не только научными исследованиями, но и разработкой и реализацией различных стратегий (отраслевых, корпоративных, региональных). Он определяет стратегию как «результат системного анализа среды, существующих прогнозов будущих условий на основе стратегического мышления, глубоких знаний и интуиции. Конечным продуктом этого анализа является формализованная стратегия, сочетающая предшествующий ей новый прогноз, миссию, видение, приоритеты и долгосрочные цели и задачи с детальным сценарием, требующим осуществления через реализацию стратегического плана с использованием системы стратегического мониторинга его законопослушной реализации» [6, с. 353].

Инновационная стратегия должна отвечать на вопрос «Какие наукоемкие изобретения будут создавать дополнительную ценность для потенциальных клиентов?». Если инновации не увеличивают спрос, не экономят средства клиентов, не отвечают национальным интересам (улучшение здоровья граждан, состояние экологии), то они не создают ценности для общества и их общественная эффективность равно нулю.

Наукоемкие изобретения могут создавать ценность различными способами, направленными на улучшение технических параметров продукта, упрощение трудоемких операций, обеспечение удобства в эксплуатации изделия, делая продукт более надежным и долговечным. Высокотехнологичные компании создают множество революционных разработок, осно- 
вываясь на стратегическом сценарии развития дополнительных возможностей. Например, американская корпорация Apple - производитель персональных и планшетных компьютеров, аудиоплееров, смартфонов, программного обеспечения, многозадачных операционных систем с графическим интерфейсом [7], фокусирует инновационные стремления на том, чтобы сделать свои продукты более простыми и удобными в использовании, в сравнении с продуктами конкурентов. Менеджмент компании делает упор на разработку проприетарного программного обеспечения и функционального дизайна.

На основе инновационной стратегии компания Apple создала в индустрии потребительской электроники свой стратегический бренд, деловой имидж и уникальную репутацию. Рыночная стоимость Apple в 2020 году впервые поднялась выше 2 трлн. долларов США [8]. Компания активно инвестирует средства в технологии искусственного интеллекта. С 2016 года по 2020 год компания Apple приобрела 25 стартапов, разрабатывающих технологии искусственного интеллекта и машинного обучения. По объему инвестиций в технологии искусственного интеллекта Apple опережает своих конкурентов (Accenture, Google, Microsoft, Facebook) [5].

Компания Apple осуществляет поглощение организаций, занимающихся технологиями искусственного интеллекта. Для совершенствования голосового помощника Siri, а также технологий искусственного интеллекта и Data Science, компанией Apple был приобретен канадский стартап Inductiv. С целью совершенствования понимания Siri естественного языка была приобретена компания Voysis [5], разработавшая платформу для цифровых голосовых помощников.

Благодаря технологиям компании Voysis цифровые голосовые помощники лучше понимают запросы пользователей и быстрее находят необходимую информацию о товарах. Технология использует данные, которые хранятся в клиентской базе и инструменты искусственного интеллекта, позволяющие распознать продукты и услуги [3]. Применение технологий распознавания данных способствует повышению эффективности обработки документации.

В 2020 году компания Apple купила разработчика технологий виртуальной (VR) и дополненной (AR) реальности NextVR. NextVR имеет опыт работы с потоковым вещанием, объединения виртуальную реальность со спортивными и развлекательными мероприятиями [1].
Одним из стратегических приоритетов инновационной деятельности компании Apple является создание акселераторов. Примером может служить запуск акселератора в Китае для содействия разработчикам в распространении прикладного программного обеспечения на глобальном рынке. Деятельность акселератора также направлена на обучение китайских разработчиков, охватывающее такие операционные системы как iOS, iPadOS, watchOS, macOS и tvOS [2].

Внимание экспертов в сфере анализа стратегических приоритетов инновационного развития высокотехнологичного сектора экономики привлекает деятельность транснациональной компании Microsoft. Компания осуществляет производство проприетарного программного обеспечения для вычислительной техники, создает игровые консоли Xbox и аксессуары для персональных компьютеров.

Компания Microsoft в своей деятельности опирается на различные инновационные направления, одним из которых является усиление механизмов защиты данных и интеллектуальной собственности. С этой целью компания заявила о покупке разработчика систем кибербезопасности RiskIQ. На решение о покупке повлияли участившиеся преступления, совершаемые в сфере информационных технологий [12]. Для усиления кибербезопасности в 2020 году компания приобрела стартап CyberX, специализирующийся на повышении надежности критической информационной инфраструктуры кибербезопасности [13].

В 2018 году компания Microsoft приобрела облачный стартап PlayFab для разработки игр в режиме реального времени и управления ими. Стартап предоставляет игровые службы и средства аналитики данных. PlayFab поддерживает игры для РС, консолей и мобильных устройств. Microsoft использует PlayFab для развития платформы Azure [14].

В 2018 году компания Microsoft приобрела стартап Semantic Machines, осуществлявший разработку технологий на основе искусственного интеллекта. Покупка стартапа позволила компании Microsoft укрепить позиции при создании чат-ботов и голосовых помощников. Проекты стартапа используются для развития сервисов Xiaolce и Azure Bot Service [15].

Стратегическим приоритетом инновационной деятельности Microsoft является запуск программы Microsoft for Startups, расширяющей 
возможности инновационных компаний и обеспечивающей доступ к технологиям [16].

Технологические инновации являются конкурентным преимуществом высокотехнологичных компаний. Но некоторые перспективные инновационные разработки могут иметь мало общего с новыми технологиями. За последние несколько десятилетий компании, такие как Amazon, Uber, Netflix достигли существенных успехов в построении инновационных бизнесмоделей [22]. Поэтому рассматривая стратегические приоритеты инновационной деятельности, у компаний имеется выбор относительно того, какой объем ресурсов необходимо направить на технологические инновации, а какой следует сконцентрировать на построении инновационных бизнес-моделей.

Наряду с технологическими инновациями, компании активно осуществляют перманентные, подрывные и радикальные инновации. Перманентные инновации базируются на управлении уникальными технологическими компетенциями сотрудников компании и соответствуют ее стратегическим приоритетам инновационной деятельности. Примером может являться выпуск американской технологической компанией Intel все более мощных микропроцессоров, предназначенных для обработки цифровой или аналоговой информации, которые позволили компании динамично развиваться на протяжении длительного периода времени.

Подрывные инновации предполагают разработку новой бизнес-модели, бросая вызов бизнес-моделям других компаний, в результате чего разрушают существующую рыночную стоимость, вытесняя признанных лидеров рынка. Например, операционная система Android компании Google, предназначенная для управления мобильными устройствами, планшетами, ноутбукам и другими электронными девайсами, подрывает работу таких компаний, как Apple и Microsoft, не из-за каких-либо существенных технологических различий, а из-за своей бизнес-модели: операционная система Android раздается бесплатно, а операционные системы Apple и Microsoft - нет [22].

Радикальные инновации являются полной противоположностью подрывных инноваций. Примером может служить появление и развитие генной инженерии и биотехнологии. Фармацевтическая промышленность всегда считалась одной из самых стабильных и рентабельных, несмотря на свою технологичность и высокую затратность. К основным тенденциям фармацевтической индустрии относят технологии искусственного интеллекта, аналитику Big Data, аддитивное производство, технологии блокчейн, расширенную реальность (XR), цифровую терапию. Стратегические направления инновационной деятельности фармацевтических компаний опираются на передовые терапевтические платформы и науку, основанную на данных.

Транснациональная фармацевтическая корпорация Novartis International AG является второй по величине в мире фармацевтической компанией, специализирующейся на создании препаратов для лечения онкозаболеваний, неврологических и эндокринных расстройств. Одним из стратегических направлений деятельности компании Novartis является строительство нового завода в США для производства инновационного радиофармпрепарата. Высокий спрос на первую целевую радиолигандную терапию потребовал расширения производственных мощностей в США, дабы сократить сроки доставки препаратов пациентам [18].

Компания Novartis заключила соглашение о стратегическом сотрудничестве с цюрихским стартапом Cellerys, осуществляющим исследования в области терапии для борьбы с рассеянным склерозом. Согласно договоренности, Novartis будет поддерживать разработку препарата CLS12311 [20]. В 2019 году Компания Novartis анонсировала программу бесплатного доступа к препарату Zolgensma для лечения спинальной мышечной атрофии. Суммарные продажи Zolgensma к сентябрю 2019 года достигли 175 млн. долларов США [21].

Реализуя стратегию долгосрочного развития, Novartis руководствуется несколькими приоритетами, позволяющими создавать ценность для компании, акционеров и общества: раскрытие потенциала сотрудников, внедрение революционных инноваций, ежедневное обеспечение операционной эффективности, использование данных и цифровых технологий, выстраивание с обществом отношений, основанных на доверии [19].

Вопросы продовольственной безопасности для общества имеют первостепенное значение. Компании, обеспечивающие продовольствием население планеты на основе принципов безопасности, ответственности и рационального использования ресурсов, решают глобальные зада- 
чи продовольственной системы. Одной из таких компаний является американская продовольственная компания Cargill, устанавливающая и развивающая отношения с другими представителями глобальной продовольственной системы и находящая решения в области экологически безопасного питания.

В 2017 году компания Cargill приобрела долю в стартапе Memphis Meats, разработавшем технологию выращивания мяса из самовоспроизводящихся клеток животных. Впервые традиционный производитель мяса становится инвестором компании из сектора «культивируемого мяса». Европейские и американские стартапы по типу Memphis занимаются разработками, позволяющими выращивать мясо с использованием методов тканевой инженерии [9].

В 2019 году компания Cargill инвестировала средства в стартап Aleph Farms, осуществляющий производство мяса с применением технологии 3D-печати тканей - это позволило Aleph Farms вывести свою продукцию на рынок [10].

Руководство компании Cargill в 2020 году приняло стратегическое решение о покупке предприятия по переработке сои в восточном Китае (Жичжао, провинция Шаньдун), ранее принадлежавшее Shandong Xinliang Oils \& Fats Co Ltd [11].

Американский химический и биотехнологический гигант Monsanto приобрел стартап Climate Corporation, который осуществлял внедрение технологий машинного обучения и Big Data в сельское хозяйство. Корпорация Monsanto получила известность благодаря своему гербициду Roundup и генно-модифицированным сельскохозяйственным культурам, которые выращиваются в сочетании с гербицидом. С момента основания было принято стратегическое решение сосредоточиться на исследованиях и разработках в области агрокультурных биотехнологий. В компании Monsanto хотят специализироваться не только на биотехнологиях и производстве пестицидов, но и на удовлетворении ключевых потребностей сельскохозяйственных предприятий. Поэтому приобретение компанией Monsanto стартапа Climate Corporation является логическим шагом в развитии бизнеса. Основным коммерческим продуктом компании является сервис Climate.com, который проводит моделирование погоды и природных агрономических показателей [17].

Инновационная стратегия высокотехноло- гичной компании должна определять, какие типы инноваций следует включить в бизнесстратегию и какие ресурсы необходимы для их трансфера, внедрения и освоения. Не существует единого алгоритма действий для определения необходимого количества ресурсов с целью создания того или иного типа инноваций. Как и на любой стратегический вопрос, ответ будет зависеть от специфики деятельности компании и таких факторов, как скорость изменений технологических процессов, особенности конкуренции, материально-техническое обеспечение, темпы роста рынков сбыта, сильные стороны компании [22]. Например, фармацевтическим и информационно-коммуникационным компаниям, сфера деятельности которых предполагает быстрое изменение базовых технологий, следует ориентироваться на возможности радикальных технологических инноваций. Компаниям, основная деятельность которых находится на стадии становления, возможно, придется искать новые стратегические возможности в инновационных бизнес-моделях и революционных технологических решениях.

При определении стратегических приоритетов инновационной деятельности ключевой задачей для высокотехнологичных компаний является определение баланса между возможностями организации и ожиданиями потребителей. Например, компания Google повышает уровень своей капитализации за счет инновационного подхода в маркетинговой стратегии, в то же время компания изучает возможности радикальных и архитектурных инноваций, таких как технологии беспилотников. Компания Apple не останавливается на достигнутом и расширяет возможности цифровых устройств и платежных систем [22]. Несмотря на то, что автомобилестроительные компании по-прежнему получают существенную часть своих доходов от продажи транспортных средств, двигатели которых работают на жидком углеводородном топливе, большинство из них переключилось на производство автомобилей, работающих на альтернативных источниках энергии (не загрязняющие окружающую среду).

Конструктивно сформулированная инновационная стратегия позволяет понять, какие методы организации деятельности с большей долей вероятности подходят для компании. Это поможет менеджменту компании найти компромиссы, например, между работой в режиме 
коммерческой тайны и открытыми инновациями. Вовлечение потребителей в инновационный процесс и тесное взаимодействие с ними позволяет компании получать новые идеи, которые могут привести к созданию высокотехнологичных разработок. В то же время, слишком тесное сотрудничество с потребителями может не позволить увидеть возможности для революционных инноваций. Некоторые компании фармацевтической отрасли, в том числе Novartis, защищают свои проектные группы от влияния результатов исследований рынка при принятии решений о стратегических направлениях деятельности [22]. Менеджмент фармацевтических компаний считает, что, принимая во внимание длительность сроков разработки лекарственных средств и сложность рынка, точные прогнозы при принятии решений невозможны.

Определение приоритетных направлений инновационной деятельности требует стратегического расчета и понимания предпочтений потребителей. Выбор инновационных проектов предполагает оценку компромиссов - рассмотрение возможных вариантов перед принятием решений в условиях неопределенности. Понимание того, какие компромиссы являются наиболее подходящими для компании, помогает в преодолении препятствий на пути трансфера, внедрения и освоения инноваций. Сопротивление изменениям в компаниях наблюдается не потому, что сотрудники не стремятся к изобретательности и креативности, а потому, что у них разные взгляды на механизмы организации инновационной деятельности. Рациональное опре- деление компромиссов, регулирование баланса интересов и выбор стратегических приоритетов являются важными шагами в использовании ресурсов компании для выполнения НИОКТР.

Таким образом, при разработке и реализации инновационной стратегии целесообразно придерживаться нескольких принципов. Первым принципом является разработка инноваций, которые будут создавать ценность для клиентов и для компании. Вторым принципом выступает создание механизма рационального распределения ресурсов для различных видов инноваций. Третий принцип предполагает поиск компромиссов и баланс интересов, и здесь важна роль высшего менеджмента, поскольку представители структурных подразделений компании будут стремиться к удовлетворению своих интересов, и только старшие руководители или акционеры могут осуществлять выбор, который лучше всего подходит для стратегического развития компании. Еще одна важная задача, стоящая перед высшим руководством, заключается в осознании того, что тактический план по реализации инновационных стратегий должен совершенствоваться из-за технологических трансформаций, темпов роста рынков, изменения правил ведения бизнеса и поведения конкурентов. Чтобы оставаться конкурентоспособными, компании должны совершенствовать не только конструкцию изделий, но и инновационные стратегии. Как и сам процесс создания наукоемких изделий, разработка инновационной стратегии предполагает экспериментирование, обучение и адаптацию к меняющимся условиям.

\section{Библиографический список}

1. Apple купила разработчика технологий виртуальной реальности NextVR / 3DNews Daily Digital Digest. [Электронный ресурс]. URL: https://3dnews.ru/1010977/apple-kupila-razrabotchika-tehnologiy-virtualnoy-realnostinextvr (дата обращения: 08.12.2021).

2. Apple запустила акселератор для разработчиков в Китае / ООО «РБ.РУ». [Электронный ресурс]. URL: https:// rb.ru/news/apple-accelerator/ (дата обращения: 11.12.2021).

3. Apple купила разработчика ИИ-платформы для голосовых помощников / TAdviser. [Электронный ресурс]. URL: https://www.tadviser.ru/index.php/\%D0\%9A\%D0\%BE\%D0\%BC\%D0\%BF\%D0\%B0\%D0\%BD\%D0\%B8\%D1\% 8F: Voysis (дата обращения: 13.12.2021).

4. William L. Shanklin, John K. Ryans, Jr. Organizing for High-Tech Marketing / IT management. [Электронный реcypc]. URL: https://hbr.org/1984/11/organizing-for-high-tech-marketing (дата обращения: 27.11.2021).

5. За пять лет Apple купила 25 стартапов по разработке искусственного интеллекта / iPhones.ru. [Электронный ресурс]. URL: https://www.iphones.ru/iNotes/za-pyat-let-apple-kupila-25-startapov-po-razrabotkeiskusstvennogo-intellekta-03-26-2021 (дата обращения: 03.12.2021).

6. Квинт В.Л. Стратегическое управление и экономика на глобальном формирующемся рынке / М.: Бизнес Атлас, 2012. 626 с. 
7. Корпорация Apple / РИА НОВОСТИ. [Электронный ресурс]. URL: https://ria.ru/20180802/1525854707.html (дата обращения: 03.12.2021).

8. Капитализация Apple превысила \$2 трлн. / Хабр. [Электронный ресурс]. URL: https:/habr.com/ru/ news/t/515852/ (дата обращения: 03.12.2021).

9. Cargill инвестирует в выращивание мяса из клеток / Ведомости\&. [Электронный ресурc]. URL: https://www. vedomosti.ru/business/articles/2017/08/23/730728-cargill-viraschivanie-myasa (дата обращения: 21.12.2021).

10. Cargill инвестирует в стартап по производству мяса с помощью 3D-печати / DairyNews. [Электронный peсурс]. URL: https://www.dairynews.ru/news/cargill-investiruet-v-startap-po-proizvodstvu-myas.html (дата обращения: 26.12.2021).

11. Cargill Inc купила предприятие по переработке сои в восточном Китае / Портал Sfera.fm. [Электронный pecypc]. URL: https://sfera.fm/news/v-mire/cargill-inc-kupila-predpriyatie-po-pererabotke-soi-v-vostochnomkitae?utm_source=facebook.com\&utm_medium=social \&utm_campaign=cargill-inc-kupila-predpriyatie-poperera (дата обращения: 26.12.2021).

12. Microsoft купит разработчика систем кибербезопасности RiskIQ за $\$ 500$ млн. / AO «Тинькофф Банк». [Электронный ресурс]. URL: https://www.tinkoff.ru/invest/news/634738/ (дата обращения: 12.12.2021).

13. Microsoft acquires CyberX to accelerate and secure customers' IoT deployments / Microsoft. [Электронный pecypc]. URL: https://www.microsoft.com/security/blog/2020/06/22/microsoft-acquires-cyberx-acceleratecustomers-iot-deployments/ (дата обращения: 12.12.2021).

14. Microsoft купила облачный стартап для игровых разработчиков / App2Top.ru. [Электронный ресурc]. URL: https://app2top.ru/industry/microsoft-kupila-startap-dlya-razrabotki-igr-v-oblake-114434.html (дата обращения: 15.12.2021).

15. Microsoft купила стартап по разработке чат-ботов Semantic Machines / ИД «Коммерсантъ». [Электронный pecypc]. URL: https://www.kommersant.ru/doc/3635463 (дата обращения: 15.12.2021).

16. Microsoft объявляет о запуске новой программы для Стартапов / B-MAG.ru - Бизнес-журнал. [Электронный ресурс]. URL: https://b-mag.ru/microsoft-objavljaet-o-zapuske-novoj-programmy-dlja-startapov-zhurnalstartap/ (дата обращения: 15.12.2021).

17. Monsanto потратит более $\$ 1$ млрд. за погодный стартап / InVenture Investment Group. [Электронный ресурс]. URL: https://inventure.com.ua/news/world/monsanto-potratit-bolee-1-mlrd-za-pogodnyj-startap (дата обращения: 27.12.2021).

18. Новартис строит новый завод для производства инновационного радиофармпрепарата / GxP News. [Электронный ресурс]. URL: https://gxpnews.net/2020/07/novartis-stroit-novyj-zavod-v-ssha-dlya-proizvodstvainnovacionnogo-radiofarmpreparata/?amp=1 (дата обращения: 17.12.2021).

19. Наша стратегия / Novartis AG. [Электронный ресурc]. URL: https://www.novartis.ru/about-us/our-strategy (дата обращения: 21.12.2021).

20. Novartis намерена приобрести разработчика препарата от рассеянного склероза Cellerys / Журнал Vademecum. [Электронный ресурс]. URL: https://vademec.ru/news/2021/06/01/novartis-namerena-priobrestirazrabotchika-preparata-ot-rasseyannogo-skleroza-cellerys/ (дата обращения: 17.12.2021).

21. Novartis планирует бесплатно раздать 100 доз препарата zolgensma общей стоимостью $\$ 210$ млн. / Журнал Vademecum. [Электронный ресурc]. URL: https://vademec.ru/news/2019/12/19/novartis-planiruet-besplatnorazdat-100-doz-preparata-zolgensma-obshchey-stoimostyu-210-mln/ (дата обращения: 21.12.2021).

22. Pisano G. P. You Need an Innovation Strategy / Harvard Business Review. [Электронный ресурc]. URL: https://hbr. org/2015/06/you-need-an-innovation-strategy (дата обращения: 27.12.2021). 